\title{
Hubungan Kecemasan dengan Pemahaman Konsep Matematika Siswa
}

\author{
Munasiah \\ Universitas Indraprasta PGRI \\ munasiahunindra@gmail.com
}

\begin{tabular}{l}
\hline \hline Article Info \\
\hline Article history: \\
Received April $18^{\text {th }}, 2020$ \\
Revised May $19^{\text {th }}, 2020$ \\
Accepted May $30^{\text {th }}, 2020$ \\
\hline
\end{tabular}

Keywords:

Anxiety;

Understanding

Concepts;

Mathematics
Abstract

Understanding mathematical concepts are the first key in understanding the material because there is a link between one concept with another concept. The implementation of learning is expected to link mathematical concepts in everyday life. Internal and external factors of students are very influential in mathematics learning, one of them is mathematics anxiety. Mathematics anxiety that is processed by students well can make these students enthusiastic to learn mathematics, but conversely, if students are not able to process mathematics anxiety properly it will negatively affect mathematics learning outcomes. The purpose of this study was to determine how much influence mathematics anxiety has on understanding mathematical concepts. This research is a descriptive quantitative research. The method used in this study is a survey method using questionnaires and questions in collecting data. The results of this study indicate that mathematics anxiety harms understanding mathematical concepts, with low chorea values. It can be interpreted that in this case, the respondent has not been able to process mathematics anxiety into motivation to continue learning to understand mathematical concepts. So anxiety has a significant effect on understanding mathematical concepts. From this research it is hoped that it can be used as a teacher's reference in carrying out mathematics learning, teachers can help reduce student anxiety by using learning models that are fun and effective, and teachers can provide motivation to students who experience mathematics anxiety. 
Kata Kunci:

Kecemasan;

Pemahaman Konsep;

Matematika
Abstrak

Pemahaman konsep matematika merupakan kunci awal dalam memahami materi, karena ada keterkaitan antara konsep yang satu dengan konsep yang lain. Dalam pelaksanaan pembelajaran diharapkan dapat mengaitkan konsep matematika dalam kehidupan sehari-hari. Faktor intern maupun ekstern siswa sangat berpengaruh dalam pembelajaran matematika, salah satunya kecemasan matematika. Kecemasan matematika yang diolah siswa dengan baik dapat membuat siswa tersebut menjadi semangat untuk belajar matematika, tapi sebaliknya jika siswa tidak mampu mengolah kecemasan matematika dengan baik maka akan berpengaruh negatif terhadap hasil belajar matematika. Tujuan penelitian ini adalah untuk mengetahui seberapa besar pengaruh kecemasan matematika terhadap pemahaman konsep matematika. Penelitian ini merupakan jenis penelitian kuantitatif deskriptif. Metode yang digunakan dalam penelitian ini adalah metode survei menggunakan angket dan tes dalam pengumpulan datanya. Hasil penelitian ini menunjukkan bahwa kecemasan matematika berpengaruh negatif terhadap pemahaman konsep matematika, dengan nilai korelasi rendah. Dapat diartikan bahwa dalam hal ini responden belum mampu mengolah kecemasan matematika menjadi motivasi untuk terus belajar memahami konsep matematika. Jadi kecemasan berpengaruh signifikan terhadap pemahaman konsep matematika. Dari penelitian ini diharapkan dapat dijadikan sebagai acuan guru dalam pelaksanaan pembelajaran matematika, guru dapat membantu mengurangi kecemasan siswa dengan menggunakan model pembelajaran yang menyenangkan dan efektif, serta guru dapat memberikan motivasi terhadap siswa yang mengalami kecemasan matematika.

\section{PENDAHULUAN}

Pendidikan adalah usaha sadar dan terencana untuk mewujudkan suasana belajar dan proses pembelajaran agar peserta didik secara aktif 
mengembangkan potensi dirinya untuk memiliki kekuatan spiritual keagamaan, pengendalian diri, kepribadian, kecerdasan, akhlak mulia, serta keterampilan yang diperlukan dirinya, masyarakat, bangsa dan negara. Oleh karena itu dalam melaksanakan prinsip penyelenggaraan pendidikan harus sesuai dengan tujuan pendidikan nasional yaitu mencerdaskan kehidupan bangsa dan mengembangkan manusia Indonesia seutuhnya, yaitu manusia yang beriman dan bertaqwa terhadap Tuhan Yang Maha Esa dan berbudi pekerti luhur, memiliki pengetahuan dan keterampilan, kesehatan jasmani dan rohani, kepribadian yang mantap dan mandiri serta rasa tanggung jawab kemasyarakatan dan kebangsaan yang diterapkan pada pelajaran matematika.

Mata pelajaran matematika perlu diberikan kepada semua peserta didik dari sekolah dasar untuk membekali mereka dengan kemampuan berpikir logis, analitis, sistematis, kritis, dan kreatif serta kemampuan bekerja sama karena dengan belajar matematika, kita akan belajar bernalar secara kritis dan aktif. Sekaligus pada saat yang sama, kita akan mengamati keberdayaan matematika (power of mathematics) dan tentunya menumbuhkembangkan kemampuan learning to learn. Salah satu faktor yang menyebabkan matematika terasa sulit untuk siswa adalah keabstrakan matematika, sehingga siswa sulit untuk membayangkan apa yang sedang mereka pelajari. Kesulitan dalam belajar matematika disebabkan karena kebanyakan dari mereka hanya sekedar menghafalkan rumusnya bukan memahami konsepnya. Oleh karena itu, agar siswa dapat memahami materi pelajaran matematika, siswa perlu ditekankan pada pemahaman konsep dan penalaran matematika dari materi yang sedang dipelajari.

Pemahaman konsep merupakan salah satu kecakapan atau kemahiran matematika yang diharapkan dapat dicapai dalam belajar matematika yaitu dengan menunjukkan pemahaman konsep yang dipelajarinya, menjelaskan keterkaitan antar konsep dan mengaplikasikan konsep atau algoritma secara luwes, akurat, efisien, dan tepat dalam pemecahan masalah (Kesumawati, 2010). Menurut Novitasari dan Leonard (2017) menunjukkan bahwa matematika perlu dipahami oleh peserta didik, oleh karena itu dalam melaksanakan pengajaran harus 
mengarah pada penguasaan konsep matematika. Karena dalam konsep matematika konsep A dan konsep B mendasari konsep C, maka konsep C tidak mungkin dipelajari sebelum konsep A dan konsep B telah dipelajari dan dipahami terlebih dahulu. Pembelajaran matematika di kelas ditekankan pada keterkaitan antara konsep-konsep matematika dengan pengalaman sehari-hari. Konsep-konsep pada kurikulum matematika dapat dibagi menjadi tiga kelompok besar, yaitu penanaman konsep dasar, pemahaman konsep, dan pembinaan keterampilan (Oktavia, 2015). Pemahaman konsep matematika merupakan landasan penting untuk berpikir dalam menyelesaikan permasalahan matematika maupun permasalahan sehari-hari. Dengan pemahaman konsep matematika yang baik, siswa akan mudah mengingat, menggunakan, dan menyusun kembali suatu konsep yang telah dipelajari serta dapat menyelesaikan berbagai variasi soal matematika (Hadi \& Umi Kasum, 2015).

Keberhasilan penguasaan konsep awal matematika pada siswa menjadi pembuka jalan dalam penyampaian konsep-konsep matematika pada materi selanjutnya. Penguasaan konsep matematika tersebut dapat dicapai jika dalam pembelajaran matematika tidak menemui beberapa permasalahan. Ada dua faktor yang mempengaruhi belajar siswa yaitu faktor dari luar (ekstern) dan faktor dari dalam (intern) siswa itu sendiri. Salah satu faktor intern yang mempengaruhi belajar siswa, yaitu kecemasan. Kecemasan matematika yaitu perasaan tegang dan cemas (sifat negatif) yang muncul ketika siswa mengalami kesulitan dalam mengerjakan soal matematika. Kecemasan matematika juga dapat disebabkan dari pengalaman saat mengerjakan soal matematika yang membuat malu karena ketidakmampuan siswa menyelesaikannya atau karena ketidakmampuan dalam menerapkan pemahaman dan penggunaan konsep matematis (Santri, 2017).

Dari paparan di atas penulis telah meneliti hubungan antara kecemasan dengan pemahaman konsep matematika siswa. Tujuan dari penelitian ini adalah mengetahui seberapa besar hubungan antara kecemasan dengan pemahaman konsep matematika siswa. Penelitian ini diharapkan dapat memberikan informasi dan masukan bagi guru dalam 
mengajar ketika menjumpai peserta didiknya yang mengalami kecemasan dalam belajar matematika.

\section{METODE PENELITIAN}

Penelitian ini dilaksanakan di SMPIT Nurul Fikri Depok, populasi sebanyak 144 siswa diambil sampel secara random sebanyak 33 siswa mengacu pada rumus untuk menentukan banyaknya responden dengan tolerance error $10 \%$. Penelitian ini merupakan jenis penelitian survei dengan pendekatan kuantitatif. Instrumen yang digunakan untuk pengambilan data dari sampel sudah divalidasi sebelumnya. Teknik pengumpulan data dalam penelitian ini menggunakan angket untuk variabel kecemasan dan tes untuk variabel pemahaman matematika. Desain yang digunakan adalah analisis regresi linear sederhana, untuk mengetahui pengaruh dan hubungan antara kecemasan dan pemahaman matematika. Penelitian ini melibatkan satu variabel bebas, yaitu kecemasan $(\mathrm{X})$ dan satu variabel terikat, yaitu pemahaman matematika (Y). Matematis dari regresi linier sederhana yang akan diperoleh sebagai berikut (Oktaviani, 2017):

$$
\widehat{\boldsymbol{Y}}=\boldsymbol{a}+\boldsymbol{b x}
$$

dengan,

$\widehat{\boldsymbol{Y}}=$ prediksi pemahaman matematika

$\mathrm{X}=$ kecemasan Matematika

$a=$ konstanta regresi

$b=$ koefisien regresi

\section{HASIL PENELITIAN DAN PEMBAHASAN}

Untuk mengetahui pengaruh kecemasan terhadap pemahaman konsep matematika digunakan uji statistik regresi linier sederhana. Data yang digunakan adalah skor data kecemasan yang dikumpulkan dari angket kecemasan, data tes soal pemahaman konsep matematika sebanyak 23 butir soal. Sebelum dilakukan uji statistik regresi linier sederhana, dilakukan uji asumsi klasik terlebih dahulu. 
1. Uji Asumsi Linier Klasik

a. Uji Normalitas

Berdasarkan perhitungan uji normalitas Kolmogorov-Smirnov SPSS 20. Didapatkan hasil sebagai berikut:

One-Sample Kolmogorov-Smirnov Test

\begin{tabular}{|c|c|c|}
\hline & & $\begin{array}{l}\text { Unstandardized } \\
\text { Residual }\end{array}$ \\
\hline N & & 33 \\
\hline \multirow{3}{*}{ Normal Parameters ${ }^{a, b}$} & Mean & 0E-7 \\
\hline & Std. Deviation & 8,54404916 \\
\hline & Absolute & ,145 \\
\hline \multirow[t]{2}{*}{ Most Extreme Differences } & Positive &, 080 \\
\hline & Negative &,- 145 \\
\hline Kolmogorov-Smirnov Z & &, 830 \\
\hline Asymp. Sig. (2-tailed) & &, 495 \\
\hline
\end{tabular}

\section{Gambar 1. Output Uji Normalitas SPSS 20}

Dari hasil output SPSS 20 menunjukkan bahwa nilai signifikansi Asymp. Sig. (2-tailed) sebesar 0,495 >0,05, maka sesuai dengan pengambilan keputusan dalam uji normalitas Kolmogorov-Smirnov, dapat disimpulkan bahwa error data berdistribusi normal. Dengan demikian asumsi atau persyaratan normalitas dalam model regresi sudah terpenuhi.

b. Uji Linieritas

Secara umum uji linieritas bertujuan untuk mengetahui apakah dua variabel memiliki hubungan yang linier secara signifikan atau tidak. Korelasi yang baik seharusnya terdapat hubungan yang linier antara variabel bebas dan variabel terikat. Berikut hasil uji linier dari kecemasan dan pemahaman konsep matematika.

Tabel 1. Hasil Uji Linieritas SPSS 20

\begin{tabular}{ccc}
\hline & \multicolumn{2}{c}{ Pemahaman Konsep Matematika } \\
\cline { 2 - 3 } & F & Sig. \\
\hline Kecemasan & 2,107 & 0,078 \\
\hline
\end{tabular}


Tabel di atas menunjukkan bahwa nilai Sig. 0,078 > 0,05, maka dapat disimpulkan bahwa ada hubungan linier secara signifikan antara variabel kecemasan dengan pemahaman konsep matematika.

c. Uji Heterokedastisitas

Dalam penelitian ini cara mengetahui ada tidaknya gejala heterokedastisitas dalam regresi menggunakan uji Glejser. Prinsip kerja uji heterokedastisitas menggunakan uji Glejser ini adalah dengan cara meregresikan variabel independen terhadap nilai absolute residual (Abs_RES). Berikut hasil output dari penghitungan uji heterokedastisitas:

Tabel 2. Hasil Uji Heteroskedastisitas SPSS 20

\begin{tabular}{|c|c|c|}
\hline & \multicolumn{2}{|c|}{ Pemahaman Konsep Matematika } \\
\hline & $\mathbf{T}$ & Sig. \\
\hline Kecemasan & $-0,233$ & 0,817 \\
\hline
\end{tabular}

Berdasarkan output di atas diketahui nilai Sig. untuk kecemasan adalah $0,817>0,05$ artinya tidak terjadi gejala heterokedastisitas dalam model regresi.

2. Uji Kelayakan

Uji kelayakan model regresi dilakukan untuk menunjukkan besarnya persentase kecemasan dalam mempengaruhi pemahaman konsep matematika yang dapat dilihat dari besarnya nilai koefisien determinasi $\left(\mathrm{R}^{2}\right)$ yang diperoleh. Berikut Tabel Output Koefisien Determinasi $\left(\mathrm{R}^{2}\right)$ :

Tabel 3. Hasil Koefisien Determinasi $\left(\mathbf{R}^{2}\right)$ SPSS 20

\begin{tabular}{rr}
\hline Koefisien Determinasi & \multicolumn{1}{c}{ Pemahaman Konsep Matematika } \\
\cline { 2 - 2 } & 0,512 \\
\hline
\end{tabular}

Tabel di atas menunjukkan bahwa besarnya koefisien determinasi adalah $51,2 \%$, artinya 48,8\% variabel $\mathrm{Y}$ yang dipengaruhi oleh varibel selain variabel kecemasan.

Untuk mengetahui ada tidaknya hubungan antara variabel $\mathrm{X}$ (kecemasan) dengan variabel Y (pemahaman konsep matematika) menggunakan teknik analisis regresi linier. Untuk perhitungan 
menggunakan SPSS 20. Perhitungan analisis regresi linier antara kecemasan terhadap pemahaman konsep matematika menghasilkan model matematis dari regresi linier sebagai berikut:

$$
\widehat{\mathrm{Y}}=188,719-1,278 \mathrm{x}
$$

Nilai 188,719 merupakan nilai konstanta yang menyatakan bahwa jika tidak ada kecemasan maka pemahaman konsep matematika akan mencapai 188,719. Koefisien regresi $\mathrm{X}$ sebesar $-1,278$ menyatakan bahwa setiap ada penambahan satu nilai untuk kecemasan akan menurunkan pemahaman konsep matematika sebesar 1,278.

Keberartian persamaan regresi diperoleh dengan menggunakan uji $t$. Hipotesis yang diuji adalah:

$\mathrm{H}_{0}$ : Kecemasan tidak berpengaruh signifikan terhadap kemampuan pemahaman matematika.

$\mathrm{H}_{1}$ : Kecemasan berpengaruh signifikan terhadap kemampuan pemahaman matematika.

Hasil perhitungan uji $t$ pada taraf signifikansi $\alpha=0,05$, sebagai berikut:

Tabel 4. Hasil Uji $t$ (Uji Keberartian Regresi)

\begin{tabular}{crrr}
\hline Uji Statistik & Nilai hitung & Sig. & \multicolumn{1}{c}{ Keterangan } \\
\hline Uji $t$ & $-5,706$ & 0,000 & $\mathrm{H}_{0}$ ditolak \\
\hline
\end{tabular}

Hasil dari uji statistik $t$ pada Tabel 4, menunjukkan bahwa nilai signifikansi $0,000<0,05$ maka $\mathrm{H}_{0}$ ditolak, yang berarti bahwa kecemasan berpengaruh signifikan terhadap kemampuan pemahaman konsep matematika peserta didik. Hal ini dipertegas dengan penelitian yang dilakukan oleh Auliya (2016) yang menyatakan bahwa kecemasan matematika berpengaruh signifikan terhadap kemampuan matematis. Pemahaman konsep merupakan salah satu kecakapan atau kemahiran matematika yang diharapkan dapat dicapai dalam belajar matematika yaitu dengan menunjukkan pemahaman konsep yang dipelajarinya, menjelaskan keterkaitan antar konsep dan mengaplikasikan konsep atau algoritma secara luwes, akurat, efisien, dan tepat dalam pemecahan masalah (Kesumawati, 2010). Menurut 
Novitasari dan Leonard (2017) menunjukkan bahwa matematika perlu dipahami oleh peserta didik, oleh karena itu dalam melaksanakan pengajaran harus mengarah pada penguasaan konsep matematika. Karena dalam konsep matematika konsep A dan konsep B mendasari konsep C, maka konsep C tidak mungkin dipelajari sebelum konsep A dan konsep $\mathrm{B}$ telah dipelajari dan dipahami terlebih dahulu. Pembelajaran matematika di kelas ditekankan pada keterkaitan antara konsep-konsep matematika dengan pengalaman sehari-hari. Konsepkonsep pada kurikulum matematika dapat dibagi menjadi tiga kelompok besar, yaitu penanaman konsep dasar, pemahaman konsep, dan pembinaan keterampilan (Oktavia, 2015). Pemahaman konsep matematika merupakan landasan penting untuk berpikir dalam menyelesaikan permasalahan matematika maupun permasalahan sehari-hari. Dengan pemahaman konsep matematika yang baik, siswa akan mudah mengingat, menggunakan, dan menyusun kembali suatu konsep yang telah dipelajari serta dapat menyelesaikan berbagai variasi soal matematika (Hadi \& Umi Kasum, 2015). Oleh sebab itu kecemasan berpengaruh signifikan terhadap kemampuan pemahaman konsep matematika peserta didik.

\section{SIMPULAN}

Hasil penelitian ini adalah kecemasan berpengaruh signifikan terhadap pemahaman konsep matematika, dibuktikan oleh hasil uji statistik $t 0,000<0,05$, besarnya koefisien determinasi yaitu $51,2 \%$ artinya 48,8\% dipengaruhi oleh variabel selain variabel kecemasan. Model regresi yang dihasilkan yaitu, $\widehat{\mathrm{Y}}=188,719-1,278 \mathrm{x}$. Nilai 188,719 merupakan nilai konstanta yang menyatakan bahwa jika tidak ada kecemasan maka pemahaman konsep matematika akan mencapai 188,719. Koefisien regresi $X$ sebesar $-1,278$ menyatakan bahwa setiap ada penambahan satu nilai untuk kecemasan akan menurunkan pemahaman konsep matematika sebesar 1,278. Adapun saran yang dapat disampaikan: (1) guru diharapkan dapat menciptakan suasana yang menyenangkan dalam pembelajaran matematika, sehingga dapat mengurangi rasa tegang dan cemas peserta didik. Guru juga harus mampu 
memberikan motivasi kepada peserta didik agar peserta didik mampu mengolah rasa cemas menjadi pengaruh yang positif pada pembelajaran matematika. Guru sebaiknya lebih mengutamakan pembelajaran pemahaman konsep, selalu mengaitkan konsep yang dipelajari dengan kehidupan sehari-hari, sehingga lebih mudah dipahami peserta didik; (2) pengontrolan faktor lain selain faktor kecemasan dalam penelitian sangat penting sehingga hasil penelitian bisa lebih akurat.

\section{DAFTAR PUSTAKA}

Auliya, R. N. (2016). Kecemasan Matematika dan Pemahaman Matematis. Formatif: Jurnal Ilmiah Pendidikan MIPA, 6(1), 12-22. https://doi.org/10.30998/formatif.v6i1.748

Hadi, S., \& Umi Kasum, M. (2015). Pemahaman Konsep Matematika Siswa SMP melalui Penerapan Model Pembelajaran Kooperatif Tipe Memeriksa Berpasangan (Pair Checks). EDU-MAT: Jurnal Pendidikan Matematika, 3(1). https://doi.org/10.20527/edumat.v3i1.630

Kesumawati, N. (2010). Pemahaman Konsep Matematika dalam Pembelajaran Matematika. Semnas Matematika Dan Pendidikan Matematika 2008, 229-235

Novitasari, L., \& Leonard. (2017). Pengaruh Kemampuan Pemahaman

Konsep Matematika terhadap Hasil Belajar Matematika. Prosiding

Diskusi Panel Nasional Pendidikan Matematika, (3), 539-548. https://doi.org/10.1007/s12293-010-0036-5

Oktavia, I. (2015). Pengaruh Model Pembelajaran Kooperatif dan Kreativitas Belajar Siswa terhadap Pemahaman Konsep Matematika. Jurnal Kajian Pendidikan Matematika, 1(1), 16-30. Retrieved from https://journal.lppmunindra.ac.id/index.php/jkpm/article/view/889/8 32

Oktaviani, K. (2017). Pengaruh Pemeriksaan Pajak dan dan Penagihan Pajak terhadap Efektivitas Penerimaan Pajak (Studi pada KPP Pratama Bandung Cibeunying periode 2013-2015). Tesis Online. Retrieved from http://repository.unpas.ac.id/30278 
Santri, F. S. (2017). Ada Apa Dengan Kecemasan Matematika? Journal of Medives, 1(1), 59-65. Retrieved from http://e-journal.ikipveteran.ac.id/index.php/matematika 
110 | Munasiah: Hubungan Kecemasan dengan Pemahaman Konsep Matematika Siswa 